\title{
ASPEK PENDIDIKAN ISLAM PROFETIK (TUJUAN, MATERI, STRATEGI, MEDIA, EVALUASI, LINGKUNGAN)
}

\author{
Mohammad 'Ulyan \\ ulyan@ittelkom-pwt.ac.id \\ Institut Teknologi Telkom Purwokerto
}

\begin{abstract}
This article discusses the aspects of prophetic Islamic education. Aspects in Islamic education are essentially a process that knows no age limit. This education is based on the Al-Quran and the Prophet's Hadith, which aims to form collective keshalehan (khaira ummah). This research was conducted using the literature study method. The results of this study indicate that Islamic education should help a Muslim be good, both for himself (shalih linafsihi) and good for others (shalih lighairihi). The prophetic education aspect which is based on the values of the Sirah Nabawiyah teachings is an integration between the components of education which are closely related to one another.
\end{abstract}

Keywords: Prophetic Religion, Education.

\begin{abstract}
Abstrak
Artikel ini membahas tentang aspek-aspek dalam pendidikan islam profetik. Aspek dalam pendidikan Islam hakikatnya merupakan suatu proses yang tidak mengenal batas usia. Pendidikan tersebut berdasarkan atas Al-Quran dan Hadis Nabi, yang bertujuan untuk membentuk keshalehan kolektif (khaira ummah). Dengan adanya pendidikan Islam diharapkan agar seorang Muslim dapat menjadi baik, baik untuk dirinya sendiri (shalih linafsihi) maupun baik untuk orang lain (shalih lighairihi). Aspek pendidikan profetik yang berlandaskan pada nilai-nilai ajaran sirah nabawiyah merupakan suatu integrasi antara komponen-komponen pendidikan yang memiliki keterkaitan erat antara satu dengan yang lainnya. Hubungan antar aspek tersebut bukan hubungan tanpa arah, namun memiliki tujuan yang mulia, yaitu membentuk manusia yang baik dan memiliki kualitas dalam bidang spiritual-keagamaan maupun intelektual.
\end{abstract}

Kata Kunci : Profetik Agama, Pendidikan. 


\section{A. Pendahuluan}

Kristalisasi ilmu yang terjadi pada akhir-akhir ini menjadi perbincangan yang cukup menarik untuk dikaji. Berbagai opini para ahli dari yang berasal dari disiplin ilmu berusaha menawarkan solusi terhadap permasalahan polarisasi ilmu menjadi dua hal yang seolah-olah berbeda dan juga bertentangan. Dikotomi ilmu muncul sebagai konsekuensi yang membawa dampak yang positif sekaligus negatif sesuai dengan keadaan dunia pendidikan itu sendiri, terutama pendidikan Islam pada era sekarang ini. Pro kontra dalam melihat pemisahan ilmu tersebut sebenarnya merupakan perdebatan dalam mencari jalan menuju kepada kemajuan umat Islam agar selamat di dunia dan akhirat. ${ }^{1}$

Salah satu alternatif yang ditawarkan antara lain melalui pendidikan yang mengintegrasikan berbagai aspek-aspek pendidikan yang berlandaskan kepada Al-Quran dan Sunnah Nabi. Dalam artikel ini akan dipaparkan mengenai aspek-aspek pendidikan islam profetik yang meliputi tujuan, materi, strategi, media, dan evaluasi serta lingkungan.

\section{B. Pembahasan}

Profetik berasal dari kata prophetic yang berarti kenabian atau berkenaan dengan nabi. ${ }^{2}$ Kata dari bahasa Inggris ini berasal dari bahasa Yunani 'prophetes' sebuah kata benda untuk menyebut orang yang berbicara awal atau orang yang memproklamasikan diri dan berarti juga orang yang

1 Muhamad Khoirul Umam, "Rekonstruksi Pendidikan Islam Integrasi Dalam Kerangka Pendidikan Profetik Transformatif” (Ina-Rxiv, 20 Mei 2018), 35, Https://Doi.Org/10.31227/Osf.Io/Vxd9g; 'Ulyan Mohammad 'Ulyan, “Aspek-Aspek Pendidikan Islam Profetik (Tujuan, Materi, Strategi, Media, Dan Evaluasi Serta Lingkungan),” As-Salam: Jurnal Studi Hukum Islam Dan Pendidikan 9, No. 1 (1 April 2020): 39; Saidatud Daroini, "Praktik Penanaman Nilai-Nilai Karakter Melalui Pembelajaran Al-Qur'an Di Pondok Pesantren Roudlotul Qur'an Jombang,” Paradigma 3, No. $1 \quad$ (22 Januari 2015): 6, Http://Jurnalmahasiswa.Unesa.Ac.Id/Index.Php/Paradigma/Article/View/10527; di dalam penelitian yang di tulis oleh Muhammad Lutffi, ia menjelaskan bahwa manfaat dan pentingnya pendidikan Profetik bagi pendidik. Muhammad Lutfi, "Urgensi Pendidikan Profetik Bagi Pendidik,” Jurnal Kependidikan 5, No. 2 (24 November 2017): 278, Https://Doi.Org/10.24090/Jk.V5i2.1934.

2 "Pendidikan Profetik Di Dusun Mlangi Nogotirto Gamping Sleman Yogyakarta | Seminar Nasional Sistem Informasi (Senasif),” 78, Diakses 6 Desember 2020, Https://Jurnalfti.Unmer.Ac.Id/Index.Php/Senasif/Article/View/202. 
berbicara masa depan. Profetik atau kenabian di sini merujuk pada dua misi yaiu seseorang yang menerima wahyu, diberi agama baru, dan diperintahkan untuk mendakwahkan pada umatnya disebut rasul (messenger), sedang seseorang yang menerima wahyu berdasarkan agama yang ada dan tidak diperintahkan untuk mendakwahkannya disebut nabi (prophet). ${ }^{3}$

Di kalangan kaum Muslim, Muhammad dikenal luas sebagai seorang pendidik. Untuk dapat dipahami secara lebih baik, Prof Dr. James E. Royster dari Cleveled State University, yang telah melakukan riset intensif tentang peran Muhammad sebagai seorang guru, teladan, dan sebagai seorang manusia ideal, telah membahas kesan-kesan kaum Muslim terhadap Nabi mereka. Dalam pengantarnya, dia menyatakan bahwa mungkin tidak ada seorang pun dalam sejarah manusia yang lebih banyak diikuti dari pada Nabinya kaum Muslimin (Muhammad). ${ }^{4}$

Tujuan dari mempelajari Sirah Nabawiyah ialah agar setiap muslim memperoleh gembaran tentang hakikat Islam secara paripurna, yang tercermin di dalam kehidupan Nabi SAW, sesudah ia pahami secara konsepsional sebagai prinsip, kaidah, dan hukum. ${ }^{5}$

Aspek dalam pendidikan Islam hakikatnya merupakan suatu proses yang tidak mengenal batas usia. Pendidikan tersebut berdasarkan atas Al-Quran dan Hadis Nabi, yang bertujuan untuk membentuk keshalehan kolektif (Khaira Ummah) ${ }^{6}$. Dengan adanya pendidikan Islam diharapkan agar seorang Muslim dapat menjadi baik, baik untuk dirinya sendiri (shalih linafsihi) maupun baik untuk orang lain (shalih lighairihi).

3 Moh. Roqib, Prophetic Education (Kontekstualisasi Filsafat dan Budaya Profetik dalam Pendidikan),(Purwokerto: STAIN Press, 2011) hlm. 46.

4 Abdurrahman Mas`ud, Intelektual Pesantren (Perhelatan Agama dan Tradisi), (Yogyakarta: LKiS, 2004), hlm. 37-38.

5 Muhammad Said Ramadhan Al-Buthy, Sirah Nabawiyah (Analisis Manhajiah Sejarah Pergerakan Islam di Masa Rasulullah saw), terj. Aunur Rafiq Shaleh Tamhid, (Jakarta: Rabbani Press, 2006). Hlm. 3.

6 Rahmayani Siregar, "Nilai Nilai Pendidikan Multikultural Dalam Alquran (Studi Analisis Tafsir Al-Maraghi)” (Masters, Universitas Islam Negeri Sumatera Utara Meddan, 2018), 29, Http://Repository.Uinsu.Ac.Id/7365/; Buhori Buhori, "Nilai - Nilai Pendidikan Amanah Dalam Al-Qur'an,” Madania: Jurnal Ilmu-Ilmu Keislaman 4, No. 2 (1 Maret 2018): 140, Https://Doi.Org/10.24014/Jiik.V4i2.4780. 
Adapun aspek dari sistem pendidikan profetik, kurang lebih sebagai berikut:

\section{Tujuan Pendidikan}

Setiap orang Islam menginginkan nilai-nilai moral dan keagamaan diajarkan kepada anak-anak mereka. Hal ini seperti yang disebutkan oleh Daun\& Walford, seperti yang dikutip oleh Kawakib: Most Muslims around the world want moral values and religious teaching in school for their children. ${ }^{7}$

Tujuan pendidikan meliputi, tujuan akhir, ultimate goals, immediate goals, dan tujuan khusus. Semua tujuan tersebut harus berjalan dan berhubungan (interrelatedness) dengan berbagai sistem sebab akibat, hukum-hukum material dan keharmonisan kehidupan praktis duniawi. Dalam konteks indonesia ada tujuan pendidikan nasional, institusional, kurikuler, dan intraksional. Tujuan pendidikan secara umum dirumuskan tujuan pendidikan itu diambil dari pandangan hidup (philosopy of life) yaitu membentuk manusia yang sempurna (insan kamil) menurut Islam. Tujuan pendidikan tersebut meliputi tujuan jasmaniah, rohaniah, dan mental atau dengan kata lain tujuan tersebut dapat diklasifikasikan pada tiga wilayah fisik-materi, rohani-spiritual, dan mental-emosional. Ketiga-tiganya harus menuju ke arah kesempurnaan. ${ }^{8}$

Hakikat dari ibadah adalah menumbuhkan kesadaran pada diri manusia bahwa ia sebagai insan diciptakan Allah khusus untuk mengabdi kepada-Nya. ${ }^{9}$

Lebih rinci lagi tujuan pendidikan Islam adalah usaha untuk membentuk akhlak mulia, persiapan kehidupan dunia-akhirat, persiapan untuk mencari rizki, menumbuhkan semangat ilmiah, dan menyiapkan profesionalisme subjek didik. Dari lima tujuan tersebut semuanya harus

40.

7 A. Nurul Kawakib, Pesantren Globalisation, (Malang: UIN-Malang Press, 2009), hlm.

8 Moh. Roqib, Phrophetic Education (Kontekstualisasi Filsafat dan Budaya Profetik dalam Pendidikan), (Purwokerto: STAIN Press, 2011), hlm. 122.

9 Mohammad Daud Ali, Pendidikan Agama Islam, (Jakarta: RajaGrafindo Persada, 2013), hlm 246. 
menuju pada titik kesempurnaan yang indikatornya di antaranya adalah bertambah baik secara kuantitatif maupun kualitatifnya. Tujuan yang telah diperinci tersebut harus dijadikan orientasi secara utuh dan terpadu. Pendidikan dikotomi tidak menjadi karakter pendidikan Islam. Hal ini karena pendidikan Islam adalah perpaduan antara jasmani, akal, akidah, akhlak, perasaan, keindahan, dan kemasyarakatan. ${ }^{10}$

Kuantitas dan kualitas yang diraih secara integratif tersebut harus dimaknai dalam kerangka beribadah kepada Allah, mendekat, dan menyatu dengan-Nya untuk mendapatkan ridla-Nya. Tujuan pendidikan Islam untuk mewujudkan manusia sebagai hamba Allah yang mampu beribadah baik dengan pikiran, amal, atau perasaan kepada Allah. Bagaimana pendidikan memproses manusia yang siap untuk berbuat dan memakai fasilitas dunia ini untuk ibadah, bukan manusia yang siap pakai dalam arti siap dipakai oleh lembaga, pabrik, atau lainnya. Jika yang terakhir ini yang terjadi maka pendidikan hanya ditunjukkan sebagai alat produksi tenaga kerja dan memperlakukan manusia bagaikan mesin. ${ }^{11}$

Semua konsep tujuan tersebut secara praktis bisa dikembangkan dan diaplikasikan dalam sebuah lembaga yang mampu mengintegrasikan, menyeimbangkan, dan mengembangkan kesemuanya dalam sebuah intsitusi yang tidak terlepas dari masjid sebagai pusatnya. Berdasarkan pada definisi tersebut di atas, maka secara umum dapatlah dikatakan bahwa tujuan pendidikan Islam adalah pembentukan kepribadian muslim paripurna (kaaffah) yang memiliki indikator kemandirian, multi kecerdasan, dan kreatif-dinamis sehingga mampu memberi rahmat bagi alam. Pribadi yang demikian adalah pribadi yang menggambarkan terwujudnya keseluruhan esensi manusia secara kodrati, yaitu sebagai makhluk individual, makhluk sosial, makhluk moralitas, dan makhluk yang ber-Tuhan yang berani untuk mempromosikan nilai humanis dan

${ }^{10}$ Moh. Roqib, Phrophetic Education...hlm. 123.

11 Moh. Roqib, Phrophetic Education,...hlm. 123. 
liberasi. Citra pribadi Muslim seperti itu sering disebut manusia insan kamil atau pribadi yang utuh, sempurna, seimbang dan selaras. ${ }^{12}$

Hal ini sangat sesuai dengan fungsi dan tujuan dalam Sistem Pendidikan Nasional yang disebutkan bahwa: ${ }^{13}$

Pendidikan nasional berfungsi mengembangkan kemampuan dan membentuk watak serta peradaban bangsa yang bermartabat dalam rangka mencerdaskan kehidupan bangsa, bertujuan untuk berkembangnya potensi peserta didik agar menjadi manusia yang beriman dan bertakwa kepada Tuhan Yang Maha Esa, berakhlak mulia, sehat, berilmu, cakap, kreatif, mandiri, dan menjadi warga negara yang demokratis serta bertanggung jawab.

\section{Materi Pendidikan}

Materi pelajaran, kurikulum, dan silabus dalam pendidikan integrasi yang diberikan oleh pendidik harus ditata dan disusun sesuai dengan jenjang, jenis, dan jalur pendidikan. Pendidikan anak usia dini haruslah berbeda dengan pendidikan sekolah dasar, menengah, dan pendidikan tinggi. Sebagai software, materi yang termuat dalam silabi merupakan bentuk operasional yang menjabarkan konsep pendidikan dalam rangka mencapai tujuan pendidikan. Objek kajian dalam materi tidak terlepas dari tujuan yang dilandasi prinsip dasar dan tujuan filsafat yang dipilih, kualifikasi pendidik, kondisi subjek didik, buku teks, organisasi kurikulum, penjenjangan, metode, bimbingan dan penyuluhan, administrasi, prasarana, biaya, lingkungan, evaluasi, pengembangan, dan tindak lanjut. Semua direncanakan dan disusun menjadi suatu proses yang dinamis-konstruktif menuju tujuan yang telah ditetapkan, baik dalam bentuk mekanisme organik maupun dalam mekanisme sistematik.. ${ }^{14}$

12 Moh. Roqib, Phrophetic Education, ...hlm. 124.

${ }^{13}$ Undang-Undang nomor 20 tahun 2003 tentang Sistem Pendidikan Nasional, Bab II pasal 3.

14 Moh. Roqib, Phrophetic Education...hlm. 126. 
Pendidikan Islam secara fungsional adalah merupakan upaya manusia muslim merekayasa pembentukan al-insan al-kamil melalui penciptaan situasi interaksi edukatif yang kondusif. Dalam posisinya yang demikian, pendidikan Islam adalah model rekayasa individual dan sosial yang paling efektif untuk menyiapkan dan menciptakan bentuk masyarakat ideal ke masa depan. Sejalan dengan konsep perekayasaan masa depan umat, maka pendidikan Islam harus memiliki seperangkat isi atau bahan yang akan ditransformasikan kepada peserta didik agar menjadi milik dan kepribadiannya sesuai dengan idealitas Islam. Untuk itu perlu dirancang suatu bentuk kurikulum pendidikan Islam yang sepenuhnya mengacu pada nilai-nilai asasi ajaran Islam. ${ }^{15}$

Dalam Undang-Undang Sisdiknas tahun 2003, kurikulum yang dikembangkan dan disusun harus sesuai dengan jenjang pendidikan dalam kerangka Negara Kesatuan Republik Indonesia dengan memperhatikan: ${ }^{16}$
a. peningkatan iman dan takwa;
b. peningkatan akhlak mulia;
c. peningkatan potensi, kecerdasan, dan minat peserta didik;
d. keragaman potensi daerah dan lingkungan;
e. tuntutan pembangunan daerah dan nasional;
f. tuntutan dunia kerja;
g. perkembangan ilmu pengetahuan, teknologi, dan seni;
h. agama;
i. dinamika perkembangan global; dan
j. persatuan nasional dan nilai-nilai kebangsaan.

Minimal ada tiga prinsip dalam merancang materi: ${ }^{17}$

a. Pengembangan pendekatan religius kepada dan meliputi semua cabang ilmu pengetahuan.

15 Al-Rasyidin \& Samsul Nizar, Filsafat Pendidikan Islam, (Ciputat: Ciputat Press, 2005), hlm. 55.

${ }^{16}$ Undang-Undang nomor 20 tahun 2003 tentang Sistem Pendidikan Nasional, Bab X pasal 36. 
b. Isi pembelajaran yang bersifat religius seharusnya bebas daru ide dan materi jumud dan tak bermakna.

c. Perencanaan dengan memperhitungkan setiap komponen.

Sebagai contoh dapat dikemukakan tentang kejadian awal manusia. Al-Quran menunjukkan bahwa Adam adalah manusia pertama yang dijadikan Allah, sementara materi yang lain secara bersamaan memberi informasi tentang manusia pertama adalah kera yang mengalami proses evousi-biologis-alamiah, sesuai dengan teori Darwin ${ }^{18}$. Kondisi seperti ini akan menimbulkan keraguan subjek didik, dan mereka dipaksa untuk memilih satu hal yang berlawanan. ${ }^{19}$

\section{Media}

Secara definitif media adalah segala sesuatu yang dapat digunakan untuk menyampaikan pesan dari si pengirim ke penerima sehingga dapat merangsang pikiran, perasaan, perhatian dan minat serta perhatian siswa sedemikian rupa sehingga proses belajar terjadi. Memang pada mulanya media dianggap sebagai alat bantu mengajar guru (teaching aids) ${ }^{20}$. Tetapi karena terlalu memusatkan pada alat bantu yang visual yang dipakainya maka orang kurang memperhatikan aspek desain, pengembangan pembelajaran (instuction) produksi dan evaluasinya. ${ }^{21}$

\footnotetext{
17 Moh. Roqib, Phrophetic Education...hlm. 126-127.
}

18 Heru Juabdin Sada, "Manusia Dalam Perspsektif Agama Islam,” Al-Tadzkiyyah: Jurnal Pendidikan Islam 7, No. 1 (2016): 200, Https://Doi.Org/10.24042/Atjpi.V7i1.1498; Agustinus Dewantara, "Filsafat Moral (Pergumulan Etis Keseharian Hidup Manusia)," 18 September 2018, 27, Https://Doi.Org/10.31227/Osf.Io/5cmby; Wahyu Hanafi, "Semiotika Al-Qur'an: Representasi Makna Verba Reflektif Perilaku Manusia Dalam Surat Al-Mā'ūn Dan Bias Sosial Keagamaan,” Dialogia 15, No. 1 (1 Juni 2017): 17, Https://Doi.Org/10.21154/Dialogia.V15i1.1182.

19 Moh. Roqib, Phrophetic Education...hlm. 127.

20 Andi Faisal Bakti, “Media And Religion: Rodja Tv’s Involvement In The Civil Society Discourse For Community Development," Jurnal Komunikasi: Malaysian Journal Of Communication 34, No. 3 (29 September 2018): Http://Ejournal.Ukm.My/Mjc/Article/View/22839; Abdul Pirol, "Institusi Media Massa Dan Pengaruhnya Terhadap Masyarakat,” Al Tajdid 1, $\quad$ No. 1 (2009): 9, Http://Ejournal.Iainpalopo.Ac.Id/Index.Php/Tajdid/Article/View/209; Iwan Setiawan, "Simbol Agama Dalam Film Pk Perspektif Meaning Dan Media,” At-Turas: Jurnal Studi Keislaman 1, No. 2 (2014): 67, Https://Doi.Org/10.33650/At-Turas.V1i2.160.

21 Moh. Roqib, Phrophetic Education...hlm.146-147. 
Alat pendidikan dengan menggunakan bantuan teknologi tinggi sesungguhnya dapat meningkatkan pula kreativitas subjek didik apabila ia ditempatkan pada posisinya yang tepat. Bahkan alat atau media untuk memutuskan suatu perkara hukum. Alat dapat mempermudah dan mempersingkat proses yang panjang dan melelahkan. ${ }^{22}$

\section{Evaluasi}

Sejak manusia melakukan usaha mendidik anak-anaknya pastilah mereka telah pula melakukan usaha menilai hasil-hasil mereka dalam mendidik anak-anak mereka itu, kendatipun dalam bentuk dan cara yang sederhana. Memang tindakan itu wajar, karena sebenarnya penilaian (evaluasi) hasil pendidikan itu tidak dapat dipisah-pisahkan dari usaha pendidikan itu sendiri, evaluasi merupakan salah satu aspek yang hakiki dari usaha pendidikan itu sendiri. ${ }^{23}$

Evaluasi pendidikan adalah kegiatan pengendalian, penjaminan, dan penetapan mutu pendidikan terhadap berbagai komponen pendidikan pada setiap jalur, jenjang, dan jenis pendidikan sebagai bentuk pertanggungjawaban penyelenggaraan pendidikan. $^{24}$

Evaluasi diperlukan untuk mengukur proses dan hasil pendidikan. Dari aspek proses, apakah prosesnya sesuai dengan konsep pendidikan profetik yang meliputi apresiasi terhadap tujuan, muatan materi, perilaku dan kualitas pendidik, pandangan dan perlakuan terhadap peserta didik, penggunaan metode dan media pembelajaran. ${ }^{25}$

\section{Lingkungan}

Lingkungan memiliki pengaruh yang sangat besar terhadap perkembangan peserta didik. Islma yang mengakui bahwa fitrah (potensi) manusia itu merupakan dua hal yang saling bertentangan satu sama lain, yaitu fitrah untuk berbuat baik (Islam) dan fitrah untuk berbuat jahat

22 Moh. Roqib, Phrophetic Education...hlm. 149.

${ }^{23}$ Khoiron Rosyadi, Pendidikan Profetik, (Yogyakarta: Pustaka Pelajar, 2009), hlm.283. pasal 1.

24 Undang-Undang nomor 20 tahun 2003 tentang Sistem Pendidikan Nasional, Bab I 
(kafir). Dalam kondisi demikian lingkungan merupakan sarana untuk mengembangkan fitrah tersebut. ${ }^{26}$

Apabila lingkungan yang melatarbelakangi perkembangan anak didik itu lebih kondusif dalam mengembangkan fitrah (potensi) secara maksimal, akan terjadi perkembangan yang positif ${ }^{27}$. Apabila lingkungan yang melatarbelakangi perkembangan anak didik itu destruktif dalam mengembangkan fitrah (potensi) itu, akan terjadi sebaliknya, yaitu perkembangan yang negatif. $^{28}$

Menurut Rosyadi, Islam lebih dekat kepada teori konvergensi (dalam dunia pendidikan), yang ditawarkan oleh William Stern, daripada teori nativisme dan empirisme yang masing-masing ditokohi oleh Schopenhouer dan John Lock. Islam mengakui adanya faktor dasar (nativisme) dan ajar (empirisme) yang akan berkembang dengan baik dalam kondisi lingkungan yang baik pula. ${ }^{29}$

Dari berbagai aspek tersebut yang membentuk suatu sistem, membentuk suatu pola hubungan keterkaitan yang mengintegrasi sehingga menjadi suatu sistem yang utuh dalam rangka mencapai tujuan dari pendidikan. Dengan adanya sistem yang baik, maka diharapkan mampu menciptakan individu yang berkualitas. Dengan diawali dari individu yang baik, kemudian membentuk komunitas yang baik pula.

Aspek pendidikan Islam yang terpadu dan profesional dengan melibatkan seluruh komponen yang terkait, sehingga tercipta generasi muslim

25 Moh. Roqib, Phrophetic Education...hlm. 151.

26 Khoiron Rosyadi, Pendidikan Profetik, hlm. 296.

27 Mukti Amini Dan Toto Pratisto, "Pengembangan Model 'Parenting Class' Pada Pendidikan Anak Usia Dini (Paud) Untuk Meningkatkan Keterlibatan Orang Tua Dalam Mendidik Anak,” Monograph, 2013, 46, Http://Repository.Ut.Ac.Id/5951/; Noni Ganevi, "Pelaksanaan Program Parenting Bagi Orangtua Dalam Menumbuhkan Perilaku Keluarga Ramah Anak (Studi Deskriptif Di Pendidikan Anak Usia Dini Al-Ikhlas Kota Bandung)," Jurnal Pendidikan Luar

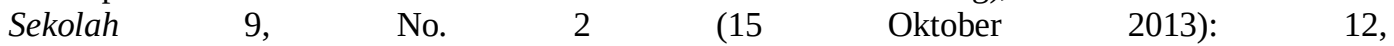
Https://Ejournal.Upi.Edu/Index.Php/Pls/Article/View/5425; Ganevi, 29.

${ }^{28}$ Ibid., Hlm. 297.

29 Ibid., 
yang berkualitas tinggi dalam iman dan taqwa serta profesional dalam iptek. $^{30}$

\section{Kesimpulan}

Aspek pendidikan profetik yang berlandaskan pada nilai-nilai ajaran sirah nabawiyah merupakan suatu integrasi antara komponen-komponen pendidikan yang memiliki keterkaitan erat antara satu dengan yang lainnya. Hubungan antar aspek tersebut bukan hubungan tanpa arah, namun memiliki tujuan yang mulia, yaitu membentuk manusia yang baik dan memiliki kualitas dalam bidang spiritual-keagamaan maupun intelektual.

30 Baharuddin, Dkk. Dikotomi Pendidikan Islam, (Bandung: Pt. Remaja Rosdakarya, 2011), Hlm. 250. 


\section{DAFTAR PUSTAKA}

Al-Buthy, Muhammad Said Ramadhan. 2006. Sirah Nabawiyah (Analisis Manhajiah Sejarah Pergerakan Islam Di Masa Rasulullah Saw), Terj. Aunur Rafiq Shaleh Tamhid. Jakarta: Rabbani Press.

Ali, Mohammad Daud. 2013. Pendidikan Agama Islam. Jakarta: Rajagrafindo Persada.

Al-Rasyidin \& Nizar, Samsul. 2005. Filsafat Pendidikan Islam. Ciputat: Ciputat Press.

Baharuddin, Dkk. 2011. Dikotomi Pendidikan Islam. Bandung: Pt. Remaja Rosdakarya.

Amini, Mukti, Dan Toto Pratisto. "Pengembangan Model 'Parenting Class' Pada Pendidikan Anak Usia Dini (Paud) Untuk Meningkatkan Keterlibatan Orang Tua Dalam Mendidik Anak.” Monograph, 2013. Http://Repository.Ut.Ac.Id/5951/.

Bakti, Andi Faisal. "Media And Religion: Rodja Tv's Involvement In The Civil Society Discourse For Community Development.” Jurnal Komunikasi: Malaysian Journal of Communication 34, No. 3 (29 September 2018). Http://Ejournal.Ukm.My/Mjc/Article/View/22839.

Buhori, Buhori. “Nilai - Nilai Pendidikan Amanah Dalam Al-Qur’an.” Madania: Jurnal Ilmu-Ilmu Keislaman 4, No. 2 (1 Maret 2018): 140-62. Https://Doi.Org/10.24014/Jiik.V4i2.4780.

Daroini, Saidatud. "Praktik Penanaman Nilai-Nilai Karakter Melalui Pembelajaran Al-Qur'an Di Pondok Pesantren Roudlotul Qur'an Jombang.” Paradigma 3, No. $1 \quad$ (22 Januari 2015). Http://Jurnalmahasiswa.Unesa.Ac.Id/Index.Php/Paradigma/Article/View/1 0527.

Dewantara, Agustinus. "Filsafat Moral (Pergumulan Etis Keseharian Hidup Manusia),” 18 September 2018. Https://Doi.Org/10.31227/Osf.Io/5cmby.

Ganevi, Noni. "Pelaksanaan Program Parenting Bagi Orangtua Dalam Menumbuhkan Perilaku Keluarga Ramah Anak (Studi Deskriptif Di 
Pendidikan Anak Usia Dini Al-Ikhlas Kota Bandung).” Jurnal Pendidikan Luar Sekolah 9, No. $2 \quad$ (15 Oktober 2013). Https://Ejournal.Upi.Edu/Index.Php/Pls/Article/View/5425.

Hanafi, Wahyu. "Semiotika Al-Qur'an: Representasi Makna Verba Reflektif Perilaku Manusia Dalam Surat Al-Mā'ūn Dan Bias Sosial Keagamaan.” Dialogia 15, No. 1 (1 Juni 2017): 1-22. Https://Doi.Org/10.21154/Dialogia.V15i1.1182.

Kawakib, A. Nurul. 2009. Pesantren Globalisation. Malang: Uin-Malang Press.

Lutfi, Muhammad. "Urgensi Pendidikan Profetik Bagi Pendidik." Jurnal Kependidikan 5, No. 2 (24 November 2017): 261-78. Https://Doi.Org/10.24090/Jk.V5i2.1934.

Mas`Ud, Abdurrahman. 2004. Intelektual Pesantren (Perhelatan Agama Dan Tradisi).Yogyakarta: Lkis.

Mohammad 'Ulyan, 'Ulyan. “Aspek-Aspek Pendidikan Islam Profetik (Tujuan, Materi, Strategi, Media, Dan Evaluasi Serta Lingkungan).” As-Salam: Jurnal Studi Hukum Islam Dan Pendidikan 9, No. 1 (1 April 2020): 33-44.

"Pendidikan Profetik Di Dusun Mlangi Nogotirto Gamping Sleman Yogyakarta | Seminar Nasional Sistem Informasi (Senasif).” Diakses 6 Desember 2020. Https://Jurnalfti.Unmer.Ac.Id/Index.Php/Senasif/Article/View/202.

Pirol, Abdul. “Institusi Media Massa Dan Pengaruhnya Terhadap Masyarakat.” Al Tajdid 1, No. 1 (2009). Http://Ejournal.Iainpalopo.Ac.Id/Index.Php/Tajdid/Article/View/209.

Roqib, Moh. 2011. Prophetic Education (Kontekstualisasi Filsafat Dan Budaya Profetik Dalam Pendidikan). Purwokerto: Stain Press.

Rosyadi, Khoiron. 2009. Pendidikan Profetik. Yogyakarta: Pustaka Pelajar.

Sada, Heru Juabdin. "Manusia Dalam Perspsektif Agama Islam.” Al-Tadzkiyyah: Jurnal Pendidikan Islam 7, No. 1 (2016): 129-42. Https://Doi.Org/10.24042/Atjpi.V7i1.1498.

Setiawan, Iwan. "Simbol Agama Dalam Film Pk Perspektif Meaning Dan Media." At-Turas: Jurnal Studi Keislaman 1, No. 2 (2014). Https://Doi.Org/10.33650/At-Turas.V1i2.160.

Siregar, Rahmayani. "Nilai Nilai Pendidikan Multikultural Dalam Alquran (Studi Analisis Tafsir Al-Maraghi).” Masters, Universitas Islam Negeri Sumatera 
Utara Meddan, 2018. Http://Repository.Uinsu.Ac.Id/7365/.

Umam, Muhamad Khoirul. "Rekonstruksi Pendidikan Islam Integrasi Dalam Kerangka Pendidikan Profetik Transformatif.” Ina-Rxiv, 20 Mei 2018. Https://Doi.Org/10.31227/Osf.Io/Vxd9g.

Undang-Undang Nomor 20 Tahun 2003 Tentang Sistem Pendidikan Nasional. 